\title{
Extended Beings: Screendance as a Reflective and Interrogative Tool During Covid-19
}

Sandhiya Kalyanasundaram, Independent artist-scholar

Keywords: screen-selves, screendance as a pedagogical tool, movement as a digital presence, sustainability, reflective pedagogy

\section{The pandemic in perspective}

In response to the Covid-19 pandemic and controlling its spread, the first school closures began in mid-March 2020 and classes shifted to home-based distance-learning models in Washington state where my children go to elementary school. Originally from South India, I have lived in the United States for 19 years and have worked closely with different communities and cultures in the context of traditional and folk dance. As a family, we are naturally curious about the world around us and our children enjoy being part of Indian cultural traditions as well as the larger milieu of cultures they are exposed to, growing up and going to school in the US. Our family spent a year (2018-2019) living and traveling within South India where the children walked through the several of the national parks, wildlife sanctuaries, and protected reserves in the Western Ghats, learning about the wildlife, trees, and the people who live in these protected forest areas. The Western Ghats is among the world's key biodiversity hotspots. During the year in India, my children also learned about traditional practices which centered on cross-species empathy and learned from environmental biologists about the issues that needed to be resolved to conserve biological diversity in the Western Ghats. As school closures dampened a sense of normalcy, my children went back and forth remembering the year in India. As a parent suddenly taking on a bigger teaching responsibility with school closures, I decided to use dance and embodied approaches to teach some basic scientific principles and develop resilience at a time of uncertainty and global climate change. In the following essay, I have outlined our engagement, storytelling for reflexive learning and using screendance as a tool for bringing in a deeper focus and understanding to special topics in childhood education/pedagogy. 


\section{Reflecting on resilience}

The few months post-March were intense as my two children grappled with what Covid19 means, listening to special CNN news segments for children and trying to figure out how a virus can impact our immune system. This was complicated with concerns about family and friends living in other countries. We played with balls to understand how Covid-19 spreads. We drew T-cells and talked about innate and adaptive immunity. We pretended to be T-cells fighting 'coronavirus balls' with light sabers. As a mom, I wanted my children to learn resiliency. As an educator, I believe in reflective pedagogy particularly in early childhood education.

For example, here is a short dialogue:

My kindergartener asked many times each day, "Will I get the coronavirus, will I have to be in hospital?"

I asked her in turn, "Do you know your body is strong and it has an immune system?"

Which led to more questions: "What is an immune system, where is the immune system in my body, does my sister have an immune system too?"

I explained that, "just like the digestive system helps you eat yummy food, get vitamins and make energy for playing all day, the immune system keeps you safe and fights bad germs." I encouraged her by asking if she would like to draw or maybe dance out what she learnt. I asked, "Can you tell me what characters we need to have for this drawing?"; she would pick herself, a germ, and the immune system. Then I would break down the immune system into smaller components such as a T-cell which would give me an opportunity to explain the idea of binding sites.

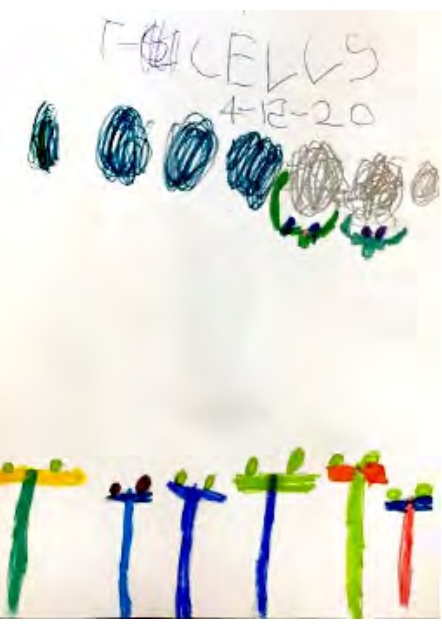

Final drawing of T-cells by my 5-year old, April 2020. 
At the end I asked, "how do you feel about Covid-19 now?" Her answers were calmer and focused on the spiky pattern of the virus, touching multiple surfaces which can lead to contact with the virus, MHC Complex, a T-cell etc. An engagement like this could last for a couple of hours and then be left behind for a whole week and picked back up another day. The advantage of this approach to teach some concepts in biology is that it gives young children the time to fulfill their curiosity and ask lots of questions. Children can also understand that there are many players in immunity and that it is not exactly a linear process or outcome. Children comprehend that there is the time to infection, the immune response and aligned processes with variable outcomes that depend on multiple underlying factors.
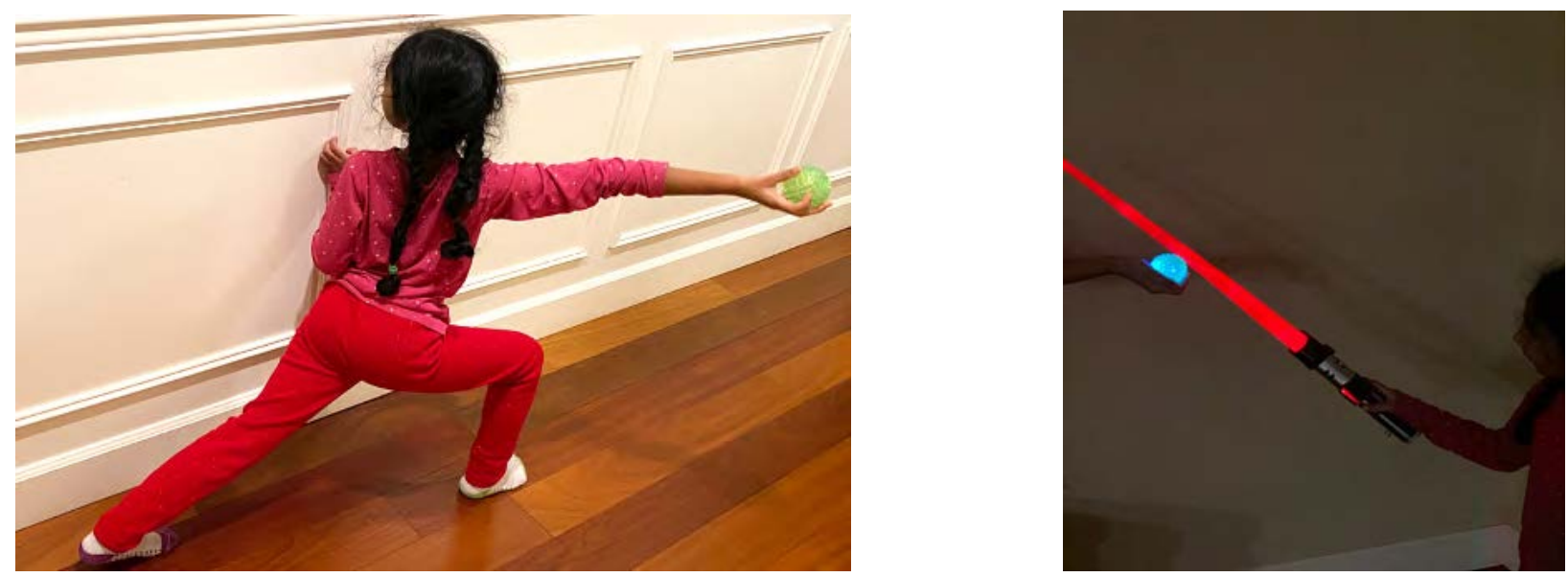

Performing coronavirus and immunity: coronavirus light-up balls and T-cell light sabers, April 2020.

When we perform this with a spiky light-up ball, it is easy to denote 2 states: an initial virus entry into host and the lit-up ball showcasing active viral replication mechanisms inside host.

While the complexity of this entire biological process cannot be taught to a kindergartener, it is still possible to develop a systems-thinking approach from a very young age.

In my work with teaching my own children as well as working with elementary school children using dance to teach science, I have found that enacting or embodying the concept goes a really long way in how they understand the concept and begin to apply it. When I work with elementary school children, this learning and application of concepts is particularly enhanced when I take videos of children in groups and play it back to them asking them to explain in words what action they were performing, how did this action make them feel, what was the outcome of this action and could they explain why the action ended up with a certain result. In a follow-up session, the video would allow me to teach the scientific method.

\section{Using Screendance tools and Embodied inquiries into sustainability}

Dance is an immanent aspect of my children's lives. From birth they have been witness to dance, to solkattu (the rhythmic syllables of Bharatanatyam footwork), and been privy to my conversations and collaborations with dancers from different cultures. They have watched 
videos of dance and the practice of dance is not a new concept or meant only for a dance lesson.

With remote learning, I structured our day around necessary school work but emphasized outdoor time hiking, biking, or simply watching birds at the bird bath. I encouraged them to express their observations through journaling, drawing, as well as play-acting or dancingsimple activities that my children enjoy-and used these expressions to create photo stories and musicals. One topic discussed often at our home is climate change, environment, and sustainability. During the remote learning months, we researched several children's books that talked about sustainability and also decided to use dance movements to interrogate what we learned more deeply. We learned about extinct and endangered species and the environmental modifications and stressors that lead to the challenges these species face. This provided a segue into conversations about many questions relevant to sustaining our planet and its biodiversity for the future children of the world. It also allowed them to enact three different human-animal conflicts, which I discuss in the sections that follow. The sections about vultures and tigers in India were directly inspired by their experience of living in India for a year and waiting to see a tiger for many hours at Bandipur National Reserve in Karnataka, India. The section about ocean pollution comes from their love for dolphins and swimming.

Working with movement exercises and using technology to capture these movements provided a lot of opportunities and time to discuss and ask several questions during this process. While my kindergartener enthusiastically embodied the animals in different scenarios, my fifth grader used the Apple iPhone 11 Pro Max 12MP camera; $f / 2.2$ aperture panorama setting to take photographs. Her favorite is the panorama feature. In her words, "I can create new and magical scenes like my imagination. I can change the perspective and make doubles or triples of the same person while they are doing different actions. When I see the pictures again, I think about many different choices."

\section{Plastic pollution in the ocean}

A dolphin swims through the ocean playfully in the opening scene surrounded by dappled light on the water. On its way it encounters plastic waste and ingests them. 


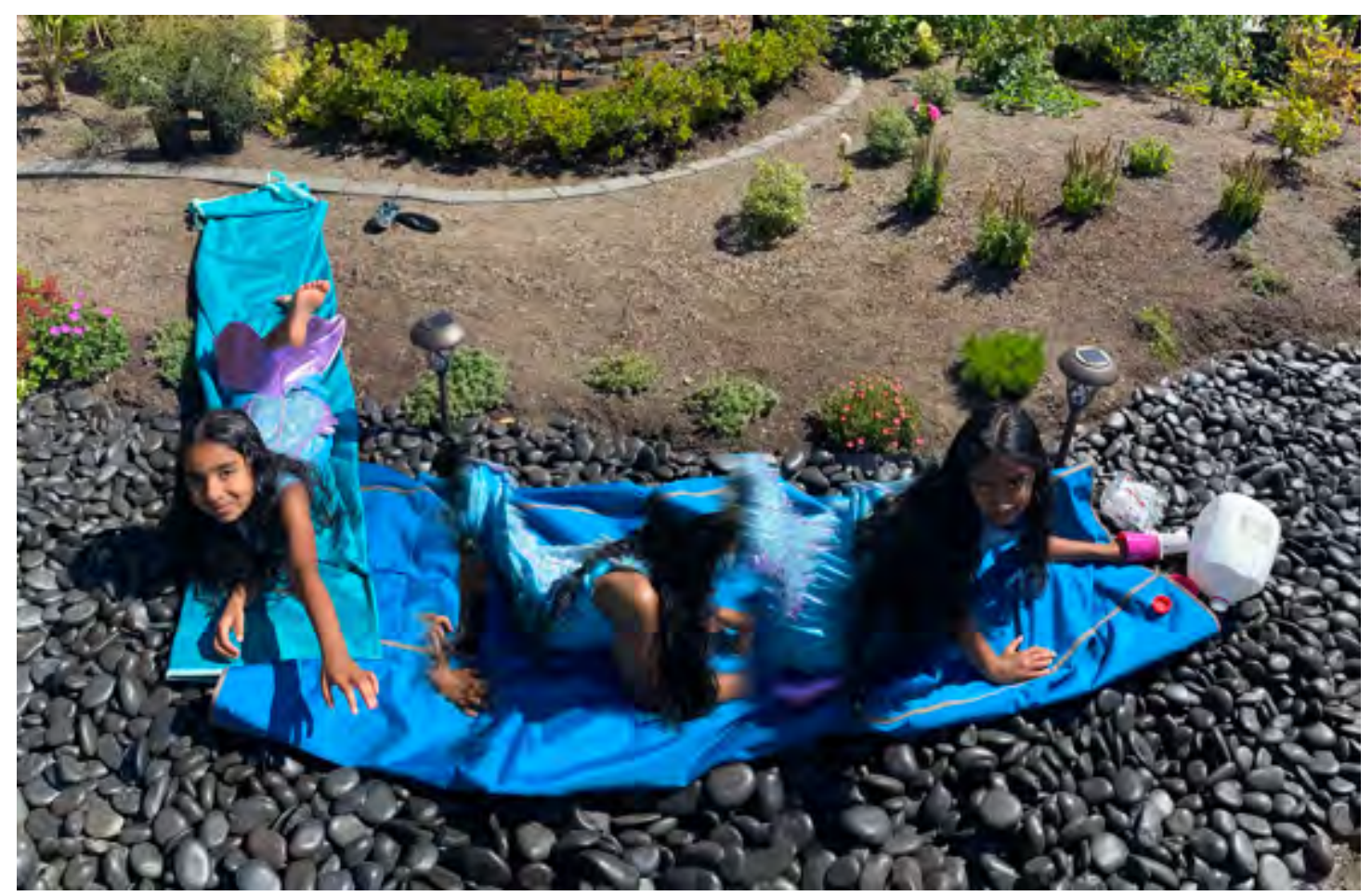

Embodying a dolphin swimming in the ocean and encountering plastic waste, May 2020. Prompts: Looking at documentaries of ocean life and plastic pollution. Discussing memories of watching ocean life from our different trips to Maldives, Hawaii and San Francisco and aquariums in India and the US. We inquire into two modes of being: 1) Cross-species empathy and 2) 'Becoming' another species. In the empathy mode, they are human beings trying to help an animal in distress while in becoming another species they dance as if they are themselves the animal experiencing the distress. Questions from the children: Why did the dolphin eat the plastic? Why does it not know that plastic is not yummy food? What will happen to the dolphin if it eats a lot of plastic? Will it get sick? Will it die? Why is there so much plastic in the ocean?

I asked them to try different movements in response to the two modes of being: 1) Crossspecies empathy and 2) 'Becoming' another species. The children explored different movements such as writhing, struggling, curling up into a ball, distress calls, carrying a hurt animal, etc. They took photographs of each other in different postures and facial expressions and actively discussed which movements looked like a dolphin, what if they could try this in the swimming pool and photograph underwater with a debate about how iPhone pictures can really show what they were feeling when they were dancing. When they shifted to dancing outdoors, they started adapting to the site, adding picnic blankets over the black stones to allow for a gliding movement and altering the length of the movements. In an interesting way, using panorama technology functioned in integrating their little minds and bodies to make sense of themselves in the context of the environment. In reflecting on the dolphin series of images, the two most important aspects of using technology and the screen that stood out in how they were learning and how their thinking was changing as a dynamic response to the screen are:

Negotiating time: The juxtaposition of the abstract inner self with variations in 'dolphin' movement captured within a single image provided the children with a human-technology 
interface that could be explored in many ways for deeper learning. Instead of a linear progression of time, there are multiple temporal frames that the children discovered and navigated. Using technology, the children broke boundaries of the self and 'became' another species, bridging the human world and the animal world with technological realities.

Multicentered gaze: Navigating the rich imagination, memories of travel and reality of their remote schooling in the US brought a multicentered gaze to how the children reflected on the panorama images. Instead of just seeing a dolphin trapped in plastic waste, the picture lent itself to the imagination of three dolphins and a variety of plastic waste making its way from around the world into different oceans. This led to further questions about rising temperatures, bleached corals, and endangered species and the need to address climate change. In the multicentered gaze, many places gathered in the location of their dance. The notion of place and identity gathered multiple layers of meaning through the eyes of my children as the real and virtual transposed and emerged new possibilities for the role of screendance in educational pedagogy.

\section{Impact of veterinary drugs on vultures}

In India, drugs such as diclofenac and ketoprofen were used widely for treating inflammation in cows. However, both these drugs cause liver damage in vultures and India saw a steady decline in all of its nine vulture species through the 1990s until the drugs were banned in 2006. Research following the ban showed that population decline had slowed or ceased in some parts of the Indian subcontinent between 2007 and 2011. ' However, complete elimination of diclofenac from the vultures' food supply has not yet been achieved. In the photograph, one child portrays a vulture spreading its wings to fly towards carrion. After feeding, the vulture feels sick and unable to fly. This was a tricky situation for the children to resolve because they felt torn between helping a sick cow with the medicine it needs and saving vultures from becoming endangered. 


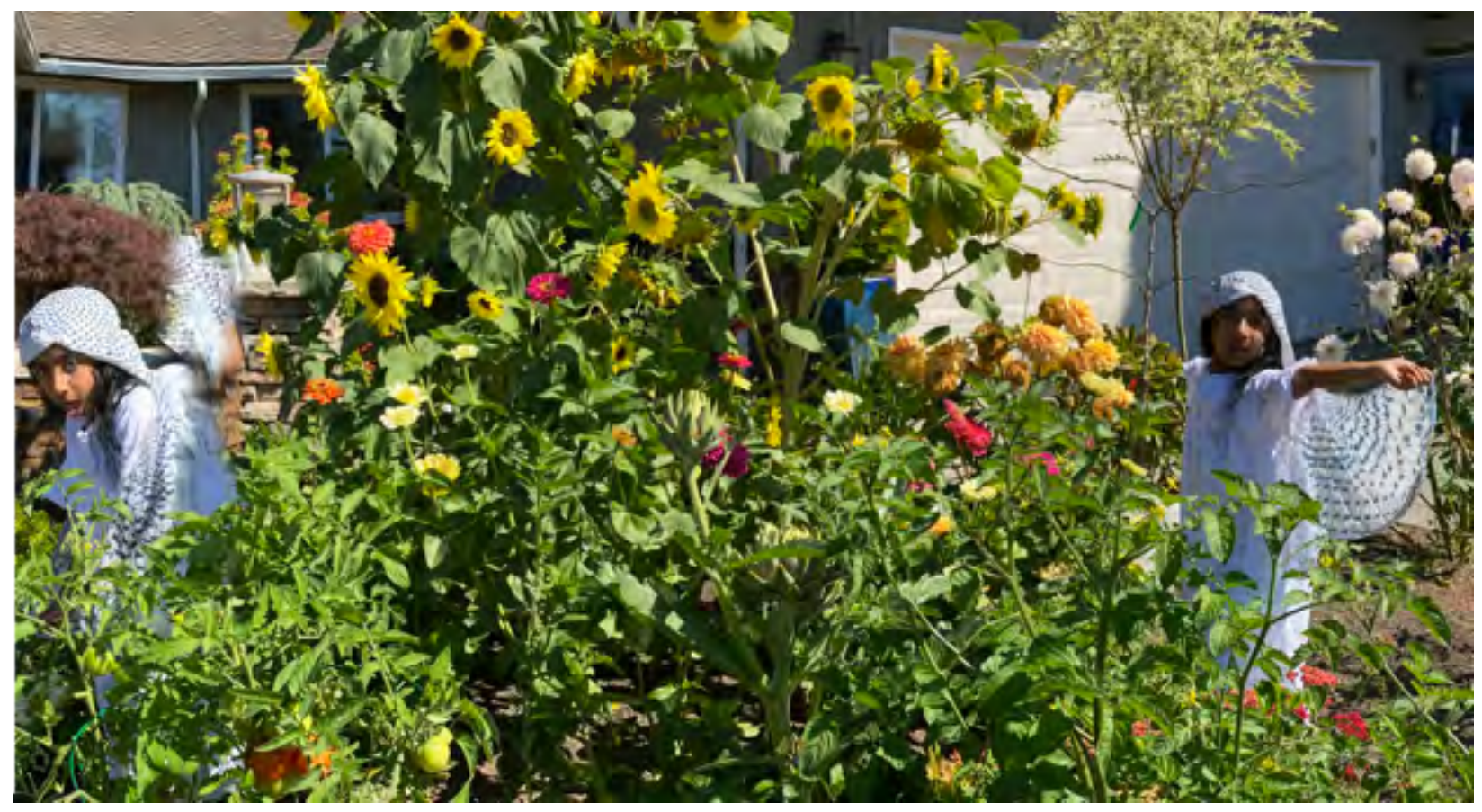

Enacting a vulture flying to feed on carrion and feeling sick later. May 2020. Prompts: What should we do if there are two animals that need to be saved, do we pick the most useful one? How should we think when we have interconnected issues? Questions from the children: Do animals that become endangered always become extinct? Is it possible to help both the cows and the vultures? Why do you say that the earth needs biodiversity?

\section{Human-wildlife conflict}

There are increasing instances of human-wildlife conflict throughout South Asia, particularly in buffer zone areas adjacent to key wildlife reserves, which are heavily utilized by farming communities or forest food-gatherers. One of the biggest concerns is declining populations of tigers as human-tiger conflicts remain unresolved. These conflicts manifest as attacks by tigers on livestock or people, or as people harming tigers. Once again, this scenario was both provocative and sad for the children as they understood that losing livestock could be crippling to poor farmers and wild plants are important sources of food, materials, and medicines for the gatherers. As they looked at their images again, the fact that each of the images captured different actions and timepoints stood out. My 5-year-old described the image in her own words for example: "The tiger is hiding in the green buffer zone. It is thinking, wait what is the tiger thinking? It must be thinking about lunch. Zoom... it is moving so fast! Oh no! it caught a poor little lamb; it is going to eat it. Mmmmm ... so yummy." 


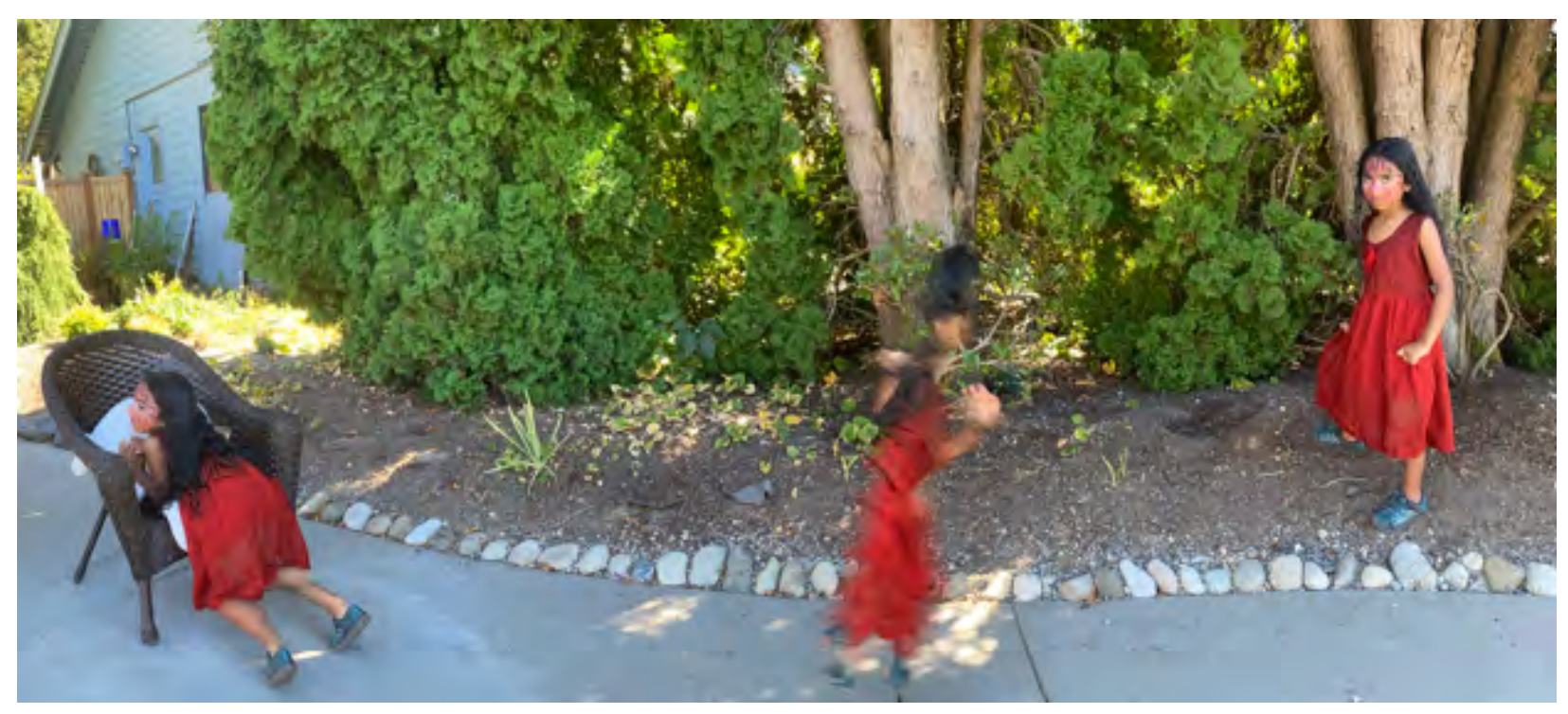

Embodying a tiger crossing the buffer zone to prey on a lamb. May 2020. Prompts: Why does the tiger attack the farmer's lamb? How much space does an adult tiger need in the forest? Questions from the children: Can we save the tiger? What can children do to help our planet? Am I a tiger or am I myself?

An interesting question that my 5-year-old posed was: "Am I a tiger or am myself?" As a child, she was easily able to move back and forth between a 'tiger state' and 'herself' and examine her movement in digital and real time and space. Being part of a generation that is so tuned to technology, my kindergartener would look at the images and tell her sister, see I look like this (making an expression or a posture) and then she would playfully come up with more jumps or rolls or more facial expressions asking, "do I look like the vulture is dying?" or "hmm how long should the tiger wait, I am hungry now-now (roar)." Her sentences conflated her identity with the identity of the animal. Also, interestingly she tried to respond to the excitement of her movement as a digital presence. This is quite a contrast with my teaching Bharatanatyam to her when I emphasize perception rooted in the physicality of the body and the tuning to inner and outer rhythm. Her conflated identities paved ways for me to think more about her movements embodying a tiger and her experiences of responding to technological capture of the scene. As an artist, understanding how, what, and why the intersection of embodiment and technology could enable the creative process is fascinating.

\section{Reflective learning using panorama images}

My fifth grader with her inquisitiveness in exploring technology has been experimenting with iPad and iPhone features to create composite, layered, and complex images of movement and locations and both my children have improvised their techniques over time to capture the stories they wish to tell. In this activity I observed her actively trying to come up with a question or an answer or an opinion before she took a photo. This attempt to have an intent was the hardest exercise. Her final image choices were the ones that she felt contained the narrative she wanted for her audience, however during the entire process, she used the panorama feature and took many images of the site and of the characters that were obscure, tilted, 
collapsed, distorted, elongated, or crooked and panned the frame to clone the characters (dolphin, vulture, tiger) into multiples. Tilting the phone to change the perspective of the image was another area of experimentation. She decided to use the panorama feature (without the add-on $360^{\circ}$ app) based on the fact that it allows for a variety of modulations. In her words, "When I tilt, I think of the iPhone like a magical machine and it lets me take pictures that are always changing. The photos can be moved, cut, copied, colored, given effects, made into an iMovie or one long attached picture for telling the stories I want. I can even tell a story in many different ways."

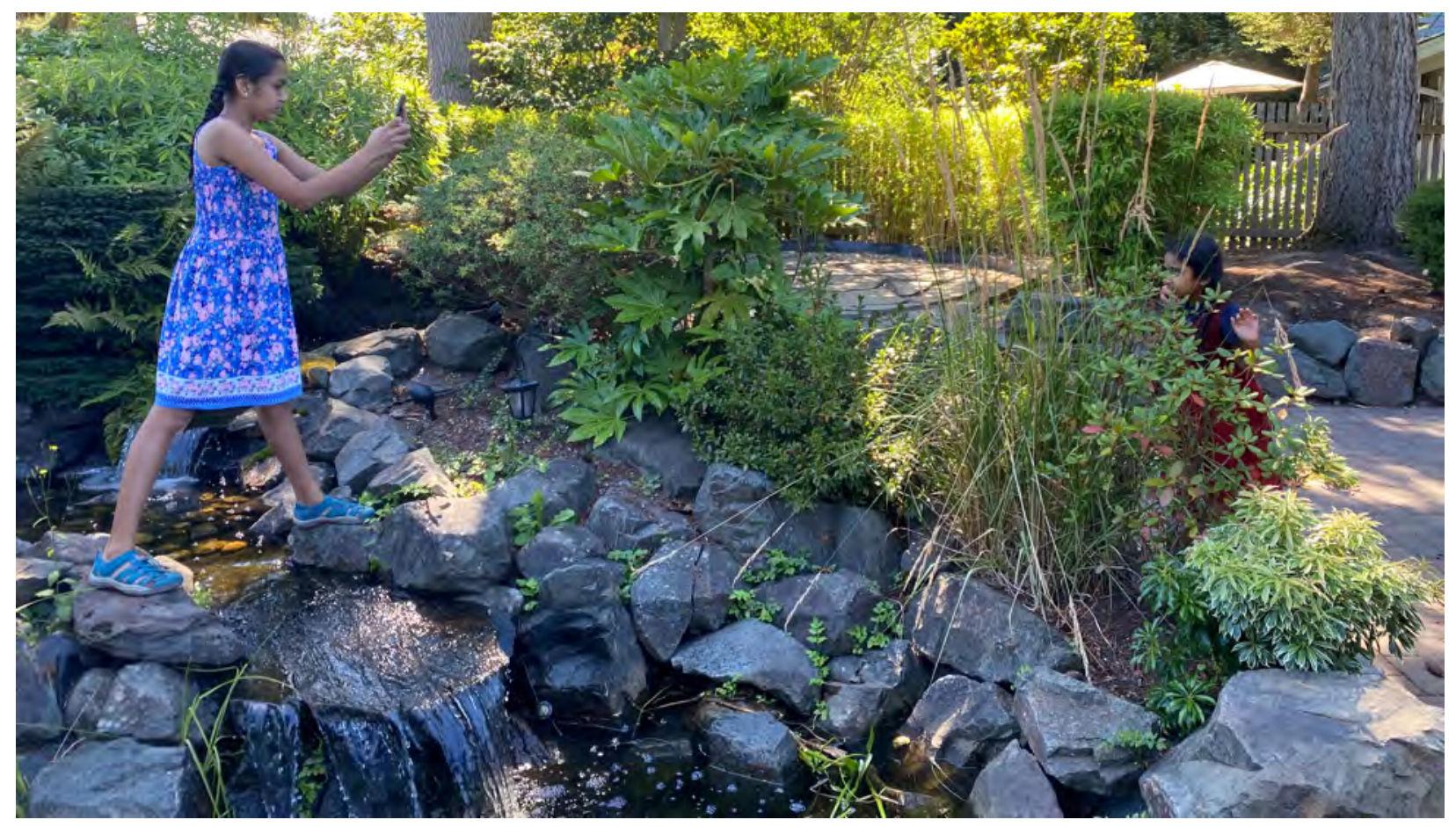

Improvising 'tiger' habitats, May 2020

The children reflected with the panorama photographs of themselves in new ways they had never done before. Their perception and experience were challenged as they integrated the dimension of technology into their thinking. Much like looking through a kaleidoscope, they use of technology allowed them to reimagine scenarios and locations in multiple ways to tell their stories. Based on their research with digital storytelling tools in early childhood education, O'Bryne et al. write, "This medium and the associated tools incorporate higher order thinking skills while also strengthening social connections in and out of the classroom."2

Panorama mode works by stitching together many individual images into a single image. In screen dance, videos or images may be edited and or modified for a differentiated perspective. One advantage with the panorama mode is that the children could have each other appear in both the left and right sides of a panorama by panning past the person and then asking them to shift their position or change their action. In the figure above, as the child enacting the tiger runs to grab the lamb, three images get stitched together to form one panorama image. The 'tiger' is prowling in the buffer zone followed by a very blurry 'moving tiger' and finally the tiger 
having captured the lamb. These images compressed and expanded time all at once while their little bodies surfaced a complexity of meanings. Douglas Rosenberg writes, "The raw data of the dancing body is stitched together in the editing process of either film or video, resulting in an impossible body." ${ }^{\prime 3}$ As the children reflected on this image, they were able to re-imagine a new 'tiger-self' for themselves on the iPhone screen and a sense of urgency in asking, what can I do to help? Blending narratives with dance movements, technological capture and active interpretation of the documentation led to a complex and nuanced understanding of humananimal conflict issues, concepts of sustainability, and inquiries into personal lifestyle and ethical choices. Combining information from categories that do not display a direct relationship, and understanding that stimuli are not independent between timepoints in the different scenarios, are essential skills for incorporating and using technology to solve problems in creativity as well as larger global issues of climate change and sustainable development. These kinds of skills can be successfully developed in young children using a combination of embodied and image processing technologies.

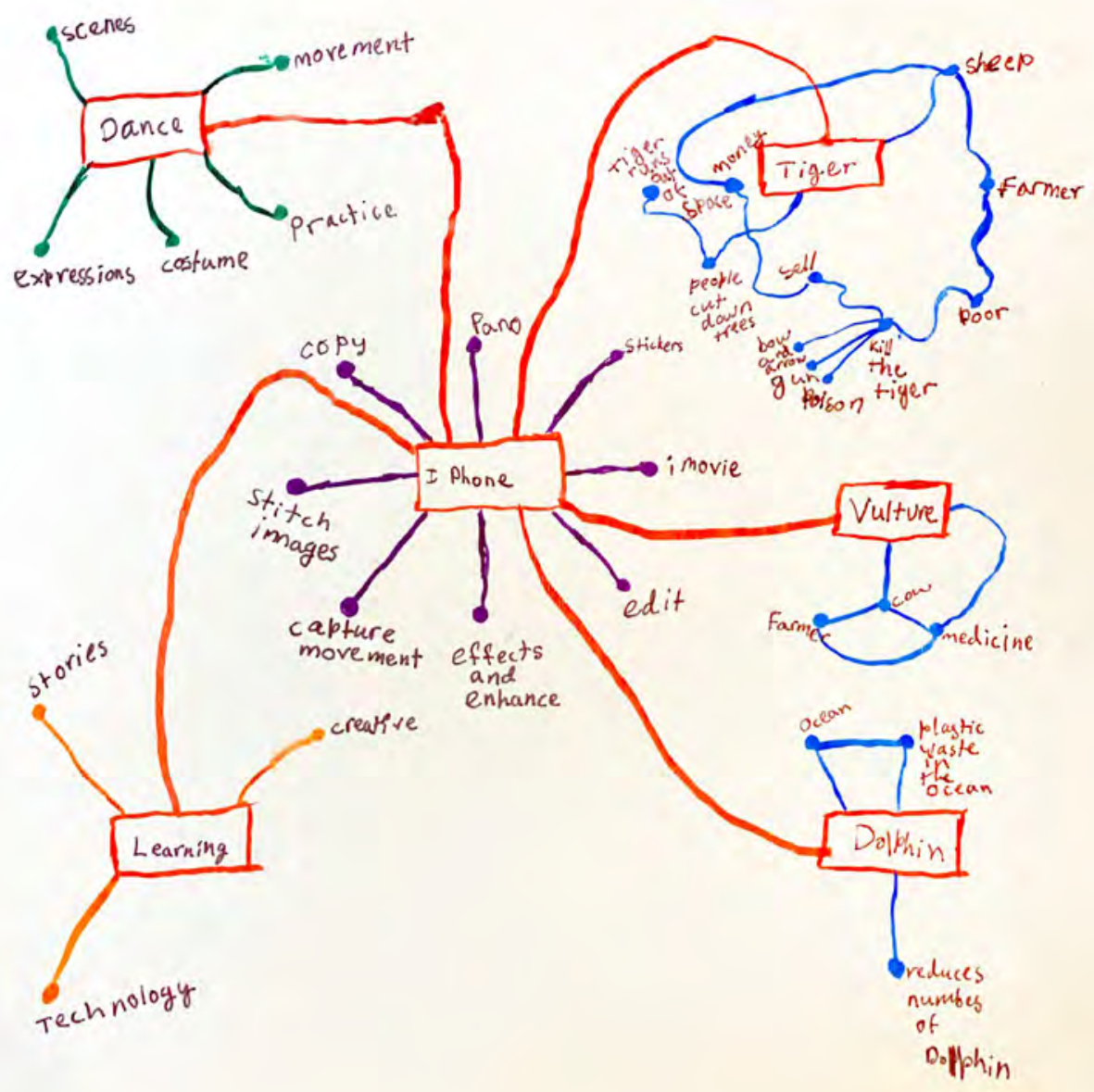

Mapping Performance, Constructing—Decoding Narratives using iPhone technology, drawn by 10-year old. 


\section{Conclusion}

Technology allows my children to intensify their experiences and find new ways to express their cognitive processing. The screen extends their bodies into a hyper virtual space-time, capturing an inner reality that is processing a complex understanding of the world. At a time when we are all forced to engage with the virtual world as a primary model for both learning and communication, screendance offers a dual space of engaging with our bodies and extending the experience into the screen, making physical experience primary to learning and communication. It also helps to re-corporealize our bodies in relation to technology.

I also see screen dance offering a challenging pedagogical tool for teachers across the world to engage with screen time without screens become invasive or overwhelmingly cognitive, providing substantial space for embodied enquiries that extend the screen as a collaborative aspect of the mind-body complex.

\section{Biography}

Sandhiya Kalyanasundaram is a dance educator, choreographer and poet. She partners with local communities to develop sustainable foodscaping and urban restoration. Before her work with the environment, she was a researcher in the field of Neuroscience. Trained in Bharatanatyam, Butoh and Flamenco, Sandhiya has led and performed in several collaborative performances between dance styles, served on the Jury Panel for the San Francisco Ethnic Dance Festival and used dance therapy to work with survivors of domestic violence. She enjoys working at the intersection of science, technology and art and is currently expanding her research into the role of dance in science education. Sandhiya's focus areas include delving into the tensions between word and meaning through dance, reflection of artistic processes, particularly imagination, improvisation and abstraction of form.

Email: sandhiyak@gmail.com

\section{Notes}

'Prakash et al., "The Population Decline."

${ }^{2}$ O'Byrne, et al., "Digital Storytelling in Early Childhood."

${ }^{3}$ Rosenberg, Screendance, 10. 


\section{References}

Lin, Maya. Whatismissing. Accessed 13 May 2020. https://www.whatismissing.net

Gabbatiss, Josh. "Animals choosing plastic as food." Accessed 28 April 2020. https://ourblueplanet.bbcearth.com/blog/?article=why-do-marine-animals-eat-plastic

Berardelli, Jeff. "Heat waves and climate change: Is there a connection?" Posted 25 June 2019. https://yaleclimateconnections.org/2019/06/heat-waves-and-climate-change-is-there-aconnection/

Yohe, Gary, Henry Jacoby, Richard Richels. "Multiple extreme climate events can combine to produce catastrophic damages." Posted 9 Oct. 2020. https://yaleclimateconnections.org/ 2020/10/multiple-extreme-climate-events-can-combine-to-produce-catastrophic-damages/

O'Byrne, W.I., Houser, K., Stone, R., and White, M. “Digital Storytelling in Early Childhood: Student Illustrations Shaping Social Interactions." Frontiers in Psychology 9 (2018). https://doi.org/10.3389/fpsyg.2018.01800

Prakash V, Bishwakarma MC, Chaudhary A, Cuthbert R, Dave R, et al. "The Population Decline of Gyps Vultures in India and Nepal Has Slowed since Veterinary Use of Diclofenac was Banned." PLOS ONE 7.11 (2012): e49118:1-10. https://doi.org/10.1371/journal.pone.0049118

Rosenberg, Douglas. Screendance: Inscribing the Ephemeral Image. Oxford University Press, 2012.

Jenkins, M., \& White, V. Can we save the tiger? London: Walker Books, 2012. 